American Journal of Economics and Business Administration 1 (3): 263-269, 2009

ISSN 1945-5488

(C) 2009 Science Publications

\title{
An Attempt to Hit Two Birds with a Stone-How Smart a Choice?
}

\author{
Avani Bansal \\ Hidayatullah National Law University, Raipur, CG, India
}

\begin{abstract}
Problem statement: This study critically analyses the choice of using the concept of 'sustainable development' for achieving both International trade promotion and environmental protection at the same time. It is my submission that the hypothesis that led to synthesis of international trade's promotion and environmental protection viz., 'economic growth leads to environmental protection' has not proved correct to which time stands as a testimony resulting in an ambiguity at the time of the conflict of two leading to the concept being used as a means of deception by the developed countries. Approach: In Part I of the study, I explain as to why was a need for such synthesis felt in the first place and how was it incorporated by calling it 'sustainable development' which has all remained mere hollow talk especially in the wake of failure of CTE and mere humble achievements of Basel, CITES, Montreal Protocol and all those eight agreements which use trade regulation as a means to achieve its objective. In Part II, I answer the question as to is there a need for an alternative due to the ambiguity prevailing in the present law, in the affirmative by resorting to Environmental Kuznets Curve and highlighting that the problem of 'Pollution Havens' can be checked even by taking an alternative route. Part III deals with this 'alternative' which is to settle the debate of priority between international trade promotion and protecting Global Commons along with addressing other environmental concerns in the favor of the latter. Part IV deals with the likely arguments against the above proposition and the solution in its wake. Results: It also suggests measures to ensure that there is no 'external free riding' in this goal of restoring our environment. Part V is the conclusion which summarizes the proposition with the observation that if trade regulations are to play an even more positive role for sustainable development, a settlement of priorities is the need of the hour. Conclusion: Thus this study advocates that the debate regarding the conflict of GATT and ETMs should be settled by clearly defining it in favor of the latter rather than leaving it for WTO panel to interpret Art. XX of GATT on a case to case basis, adopt a clear policy on international use of environmental taxes and international recognition and enforcement of polluter pays principle.
\end{abstract}

Key words: Sustainable development, MEAs, international trade, GATT, ETMS, environment Kuznets curve

\section{INTRODUCTION}

Part I: Emergence of 'sustainable development'-A Mere eyewash?

Before sustainable development: Emergence of 'free trade' and 'environment protection' as concepts on global scale: Trade and environment are two themes that has dominated the thought of mankind for generations. They seem to be as old as humanity itself $^{[1]}$. When first two human beings would have exchanged something, that would have been the beginning of 'trade' and when they would have halted to appreciate the beauty of a nature around them or watch a tree growing with surprise, that would have been the emergence of first thoughts towards 'environment protection', ${ }^{[2]}$.
From then to today, things have a changed a great deal and so has humanity. However the purpose of this study will be served if we trace the emergence of these two concepts on the world forum. From Adam Smith, who is considered to be the originator of the concept of 'free trade' based on 'principle of comparative advantage' to the WTO mechanism, all barriers to trade have only come to weaken and so has the number of its critics. On the other hand, though there were some bilateral and multilateral treatise on preserving birds ${ }^{[3]}$ and fur seals ${ }^{[3]}$ in the beginning of the 20th century, International Environmental Law has had only recently captured the imagination of the thinkers around the globe $^{[3]}$. It is surprising that environment protection was not an issue on the UN agenda when it was established over 50 years ago and so the UN was not given a specific mandate to address issues concerning the 
environment though it had carved out a role for itself by widely interpreting its preamble and articles such as 1(4), and 3 of the Charter to the $\mathrm{UN}^{[4]}$. However the Stockholm Conference in $1972^{[5]}$, marks the birth of International Environmental Law from where world community has never looked back in this sphere of 'environment protection.' But so far so good, the question arises as to why was a need felt for bringing these two concepts together?

Birth of 'sustainable development': Providing a link between environment and development issues: The Maltese proposal at the UN General Assembly 1967 contended that "there is a common heritage of mankind" which requires legal protection. In the words of M. Schroder Sustainable Development is a principle, action and instrument "to secure conditions" for the survival of future generations of Mankind ${ }^{[3]}$.

Stockholm declaration on human environment gave impetus on: Control of pollution and conservation of natural resources and socio economic development which is the key element of environment protection ${ }^{[3]}$.

The Montreal Protocol, 1987 aimed at the elimination of ozone depleting substances. The term "Sustainable Development" with reference to environment was rolled into circulation in the World Commission on Environment and Development (Brundtland Commission) in 1987. However this term 'Sustainable Development' was defined by Rio Declaration, in 1992, in the following words-"an action to secure the conditions for survival of future generation $^{[6]}$. Purpose of the 1992 UN Conference on Environment and Development (UNCED or Rio) was to revisit the environmental issues raised at the 1972 Stockholm Conference and provide a better linkage of environmental and developmental issues. One commentator observed that UNCED "may mark the eruption of vastly complex issues of environmental management and sustainability into every nook and cranny of international economic relations"[7]. The establishment of the Commission on Sustainable Development and ten years later, the convening of the World Summit on Sustainable Development in Johannesburg, South Africa, attest to the validity of the observation, at least theoretically ${ }^{[8]}$. UNCED did reach its goal, at least in part, be establishing "irrevocably the connection between environmental protection and economic growth",[9].

Synthesis of free trade and environment protection: How and why? The synthesis emerged from adoption of Agenda $21^{[10]}$ by the world community, which calls for making trade and environment mutually supportive. It states:

"An open, multilateral trading system makes
possible a more efficient allocation and use of
resources and thereby contributes to an
increase in production and incomes and to
lessening demands on the environment. It thus
provides additional resources needed for
economic growth and development and
improved environmental protection. A sound
environment, on the other hand, provides the
ecological and other resources needed to
sustain growth and underpin a continuing
expansion of trade. An open, multilateral
trading system, supported by the adoption of
sound environment policies, would have a
positive impact on the environment and
contribute to sustainable development (Id. Para
2.19)"

Agenda 21 cautions that trade restrictions should address the "root causes of environmental degradation so as not to result in unjustified restrictions on trade (Id. Para 2.20) and be implemented with care. Agenda 21 also calls on GATT/WTO to "develop more precision, where necessary, and clarify the relationship between GATT provisions and some of the multilateral measures adopted in the environment area (Id. Para 2.22(2) and to "ensure that environmental policies provide the appropriate legal and institutional framework to respond to needs for the protection of the environment that may result from changes in production and trade specialization (Id. Para 2.22 (8). Following the Rio Summit, UNEP has been collaborating with WTO and the United Nations Conference on Trade and Development (UNCTAD) ${ }^{[11]}$ on trade and environment issues, with a view to ensuring that trade and environment policies become mutually supportive ${ }^{[13]}$. Thus the question arises as to why was this need to synthesize these two branches felt in the first place especially when champions of the growth and liberalization of international trade and those equally passionate about the environment have traditionally carved separate paths, finding little in common $^{[14]}$. For proponents of liberalizing international trade, focus on the environment meant a potential adverse impact on world trade. Environmentalists on the other hand, generally perceived the liberalization, growth, and integration of world trade as a threat to the environment $^{[12]}$.

The hypothesis that underlies this synthesis is that increased trade leads to greater wealth, thus allowing a 
state to undertake environmentally protective measures and resulting in a win-win situation (United Nations Environment Programme (UNEP) and International Institute for Sustainable Development (IISD), Environment and Trade-A Handbook, at 4, 2000. The trade perspective: "Trade can actually be good for the environment, since it creates wealth that can be used for environment improvement, and the efficiency gains from trade can mean fewer resources used and less waste produced"; S. Charnovitz, The Environment v. Trade Rules: Defogging the Debate, 23 ENVTL.L. 475 (1993). See also John Young, Sustainable Development and Green Politics in The Environment-Global Problems and Local Solutions, ed. James E. Hickey Jr., and Linda A. Longmire, Greenwood Press, London, pp.25-33, wherein he states "Like most of the current advocates of sustainable development, Hawke argues that since environmental reform is going to be expensive we need, if anything, faster growth rates in order to pay for it. This is rather like telling a fat man that if he wants to get thin, he will need to eat more, so that he has the energy to take some exercise so that he can lose some weight" at 27-28). A second argument advanced in favor of this synthesis is that trade restrictions will facilitate implementation of environmental agreements (Stuart Bell and Donald McGillivray, Environmental Law, Edn., 5th, Universal Law Publishing Co. Pvt. Ltd., Indian rep. 2001. Wherein the author states that-"A potent mechanism for making international agreements effective is the prospect of trade restrictions being imposed against non-compliant states, and some treaties make provision for such restrictions". At 105) and also that trade agreements involve many countries working together for a common interest, which in turn provide a convenient for a in which to discuss other common interests as well, such as the environment. A third argument is that liberalized trade fosters "common standards for environment protection," which all states must meet (Charnovitz, supra note 27 at 576) ${ }^{[15]}$.

Has this synthesis served its purpose? The experience with international environment agreements invoking trade measures has been largely that they are of doubtful impact although the impact on environmental trade is not too insignificant. The fact is that some of the soft provisions of hard laws, and some of the soft laws themselves, tend to lay foundations for more coherent and effective international environmental laws ${ }^{[16]}$. But the question still arises as to how long will we take in building on this foundation or will we ever have a body of international environmental laws that will be effective in answering the relevant questions?
After analyzing the reasons that were advanced for the synthesis of trade and environment, it is imperative to analyze how well has this synthesis achieved what it had sought to achieve-a balance between the two.

Right from the beginning, this argument in favor of the synthesis has not been without criticism. The perspective of the environmentalists simply stated is this-"Trade means more goods produced and thus in many cases more environmental damage. The wealth created by trade will not necessarily result in environmental improvements ${ }^{[17]}$. Thus there is, to begin with, opposition to the very idea of synthesis. Then there is a question of 'implementation' of this idea of 'sustainable development'.

Firstly, although Agenda 21, contains the detailed agreement of over 170 countries to pursue the goal of sustainable development, it is largely hortatory and recommendatory in nature and does not purport to bind UNCED participants to particular actions ${ }^{[18]}$. Over after more than 10 years after the adoption of this noble document, the gap between rhetoric and reality in promoting sustainable development has only widened Supra note 8 at 626$)^{[19]}$.

Secondly, Committee on Trade and Environment $(\mathrm{CTE})^{[20]}$, even after more than a decade of its existence has failed to come up with any substantial recommendations. Directed by the Marrakesh decision to report to the first WTO Ministerial Conference in Singapore 1996, the report of the Committee summarizes the result of the two years of deliberation as follows: 'Work in the WTO on contributing to build a constructive policy relationship between trade environment and sustainable development needs to continue $^{,[21]}$.

Thirdly, the Commission on Sustainable Development (CSD) which was created to monitor the implementation of Agenda 21 and to integrate the roles of different actors in the linking of environment and development has not achieved its goal ${ }^{[22]}$. While its scope and jurisdiction are broad, the tremendous responsibilities assigned to the CSD far exceed the modest resources it has for implementing them. Furthermore it was not given any power or authority with which to discipline member states who failed to comply with Agenda 21. As a result of these two issues, the CSD has little influence over the governing bodies of international organizations such as the World Bank Groups and the World Trade Organizations. Furthermore, the submission of country reports to the CSD is done on a voluntary basis, and the decision about what material to include them is entirely discretionary. Not surprisingly, these reports tend to be 
long on self-congratulation and short on substantive analysis of remaining challenges ${ }^{[23]}$.

Fourthly, there is a fear that trade rules will lead to Multinational Companies (MNCs) seeking out countries with weak regulatory standards for products and production processes, often in developing countries, in order to lower their compliance costs leading to more production in areas with lower standards. This might also trigger 'race to bottom' in lowering standards and harmonization of laws around these low standards ${ }^{[24]}$. Therefore the synthesis of the two is important to protect the environment.

Fifthly, there is a fear that the laws of developed countries which create higher standards domestically or try to promote environmental goals abroad will be challenged as disguised protection that violates trade rule, and thus environmental protection will be undermined in this way as well. The US-Gasoline case is an example of the former, the Tuna/Dolphin and Shrimp/ Turtle case are examples of the latter ${ }^{[25]}$.

It can thus be seen that in spite of the noble intents, nothing concrete has been done to convert them into reality. No systematic study has been undertaken to see the extent to which the eight conventions which use trade measures to protect environment such as BASEL, CITES, Montreal Protocol etc. have been successful in realizing their goal.

Part II: IS there a need for an Alternative? Let's set our priorities right: After tracing the history behind the concept of 'sustainable development' and analyzing the ground reality, a question of paramount importance is how the WTO/GATT system will accommodate MEAs that employ trade restrictions, especially in the wake of the most favored principle and the national treatment principle (Ibid at 705$)^{[15]}$. No WTO/GATT dispute resolution panel yet has directly addressed the conformity of any MEA trade restrictions with GATT rules and the validity of some MEA trade restrictions is at least doubtful, in particular those involving process and production methods, discrimination between parties and non-parties and extra-territorial application ${ }^{[26]}$. Thus Article XX (b) and (g) of the GATT will have to be interpreted on a case-to-case ${ }^{[27]}$ basis for balancing trade and environment (where the researcher state: Owing to the lack of recommendations from the CTE to date on various trade and environment issues, compounded by the delay in launching a new round of trade negotiations, it has been argued that the relationship between trade and environment in the WTO is, in effect, being created through disputes)". It will not be difficult for anyone to guess, that when such a question will be left for WTO dispute settlement body to decide upon, which way will the balance tilt ${ }^{[28]}$. This skepticism has all reasons to hold ground and there is absolutely no reason why this skepticism should not be given rest by clearly setting our priorities and finding an answer to this question, rather than letting it hang in doldrums.

The need for a relook on this forged synthesis also arises from the fact that the Environmental Kuznets curve which posits the idea that during the process of economic development, the quality of the environment initially deteriorates as pollution emissions increase and then after some time the environment improves again as the economy achieves higher levels of income and development, has not proved itself over these decades. USA, a developed country is facing and contributing to environmental degradation just as any developing or underdeveloped country is. Some studies have also indicated that though some pollutants seem to become less of a problem with any economic growth; others simply get worse with economic growth without any apparent limit; and some that look like they obey the EKC may stop doing so and follow an unpleasant $\mathrm{N}-$ curve pattern instead ${ }^{[29]}$.

Thus to continue with this synthesis on two thesis viz. (1) free trade will promote economic development and (2) economic development will lead to environment protection seems to me nothing but a mere eye wash created by the developed countries who continue to pocket the benefits of economic development at the cost of the developing and underdeveloped countries.

Part III: What is the alternative? The way ahead: This might sound as just another attempt to undo all those attempts so far that tried to create a balance between the competing interests-free trade and environment protection. It might also sound like an attempt to negate all the arguments in favor of free trade and its benefits and thus challenge the wisdom behind free capitalistic world economy. If it does, it would have served its purpose.

The alternative that I wish to propose to this 'synthesis model' is very simple. It is to settle this debate of priorities between free trade and environmental protection in favor of the latter. To take it one step further, it is to give priority to environment protection over and above everything else. It is to understand the urgency required to save our planet earth, to save it for this generation. I am no scientist, no environmentalist, who is armed with all the statistics that reminds us of the grim situation that our world is facing today in the wake of imminent environmental hazards, for this has already been done. I am only a citizen who knows that she like everyone else has only 
been overly optimistic, having convinced herself, that all the problems that are being talked about will not lead in my extinction, which reduces all my fears, because then it is not my problem! But like everybody else, I also sense the fast approaching danger or calamity, call it by any name. And thus I do not think that it needs an International conference to understand this simple thing. However it definitely does need an International conference to propagate this simple idea. The details can always be chalked down, structures built, mechanism discussed. But it is the approach that to my mind is important. And the proposed model calls for a leap towards an eco-centric approach in all that the international community do, saying goodbye to the anthropocentric approach that has dominated our minds for too long.

Part IV: Do I see frowned faces and raised eyebrows? Possible arguments in dissent: Amongst many possible arguments against the proposed model, I have deliberated on the two most important of themThere is a possibility that even those who agree with the proposed model may not be sure if this will not be misused by the nations. For example, Seymour J. Rubin states-'There can hardly be a quarrel with the proposition that, in many cases, the requirements of environmental policy take precedence over the desiderata of world trade. Nonetheless, a measure that speaks to environmental protection may well be aimed principally at trade restriction... Other measures may have indeed environmental or other legitimate societal goals as their justification, but may have restrictive trade effects beyond those required by the environmental objective ${ }^{[30]}$. This to my mind brings out the essence of the major possible opposition to the proposed model. He further suggests way to deal with this problem. Though this problem is a genuine one, solutions are available in the model itself. If we have convinced ourselves of the importance that we have accorded to environment protection, then we should not declare a policy of a nation aimed at environment protection to be illegal merely because it also restricts trade. Secondly, for those policies that are aimed at trade restriction, but also serve the goal of environment protection, also should be allowed as it fits in the model. However, in the third category of the cases, where the environment protection is only minimal with huge losses in trade to the country against whom the ban is issued, there should be a fair appraisal of the facts. However it should be done not by WTO, but rather by an independent body. It might be said that this is nothing but again balancing of competing interests, however to my mind, in this model, we haven't treated both free trade and environment protection as being on equal pedestal, rather we have tilted the balance clearly in favor of the latter, with some exception regarding the third category.

A second possible argument is that those countries who do not adopt this model may give rise to the problem of 'Pollution havens' i.e., the country might attract more investment by lowering its standards as opposed to those countries who are adhering to strict and hard environmental laws ${ }^{[31]}$. This would give the advantage of 'external free riding' to those who do not follow the model, thereby further bringing down the incentive of those who do. The solution to this problem lies in making the model universally applicable though a body of agreements aimed at creating a jurisprudence of hard environmental laws. However in order to punish the non-compliant states, it is not the trade restrictions that need to be adhered to, as several other option exist in International law which can be implemented by the UN.

\section{CONCLUSION}

Part V: Is the problem so simple? Yes the problem is really that simple. What we need today is not the synthesis of free trade and environment protection rather a symbiosis ${ }^{[32]}$ between man and his environment. Dr. Paul Sears of Yale University has written:

Any species survives by virtue of its niche, the opportunity afforded by its environment. But in occupying this niche it also assumes a role in relation to its surroundings. For further survival it is necessary that its role at least be not a disruptive one. Thus, one generally finds in nature that each component of a highly organized community serves a constructive, or at any rate, a stabilizing role. The habitat furnishes the niche, and if any species breaks up the habitat, the niche goes with it. .....That is, to persist they (ecological communities) must be able to utilize radiant energy not merely to perform work, but to maintain the working system I reasonable good order. This requires the presence of organisms adjusted to the habitat and to each other, so organized as to make the fullest use of the influent radiation and to conserve for use and re-use the materials which the system requires. The degree to which a living community meets these conditions is therefore a test of its efficiency and stability ${ }^{[37]}$.

We have often heard statements like these but still we refuse to believe and understand this simple truth. 'Environmental spiritualism' can be the only answer, the panacea of all our ills (where the researcher describes environmental spiritualism as-"Spiritually 
speaking, the quintessence of the environmental movement, in its widest sweep, is that everything belongs to the Supreme Self and performs its Karma with a functional nexus. In practical terms, there is a purpose for everything in Nature too sacred to be destroyed)". Therefore if our natural resources are to be preserved, and mother earth has to live, we need to fix our priorities, give up hypocrisy, and should not exhaust all our energy in developing concepts that we don't want should work. Even if we do want them to work, then we should make all attempts to do so. But after our experiences for all these decades, I think there is a need for a change-a change in our attitude-lets us stop hitting two birds with a stone: One at a time. And that one, as long as it is in our hands should be preserved.

\section{REFERENCES}

1. Richard, M.A. and K. Brown, 1997. Approaches to Sustainable Development. Printer, London and Washington, ISBN: 1855674394, pp: 313.

2. Ashok, J. and A. Desai, 1998. Environmental Jurisprudence. Vikas Publishing House Pvt. Ltd., The University of Michigan, pp: 314.

3. Alexander Kiss and Dinah Shelton, 1991. International Environmental Law. 3rd Edn., Transnational Publishers, Inc., ISBN: 1-57105309-3, pp: 541.

4. Alam, S., 1959. The United Nations' approach to trade, the environment and sustainable development. ILSA J. Int. Compar. Law, 12: 607639. http://hdl.handle.net/1959.14/11419

5. "United Nations Environment Programme, 1972. Stockholm declaration on the human environment adopted by the United Nations conference on the human environment.

http://www.unep.org/Documents.Multilingual/Defa ult.asp?DocumentID=97\&ArticleID=1503

6. Philippe Sands and Paolo Galizzi, 2004. Documents in International Environmental Law. 2nd Edn., Cambridge University Press, Cambridge, ISBN 0-521-83266-7, pp: 1396.

7. Towards Sustainable Development, 1987. Our World Future: World Commission on Environment and Development. Oxford University Press, New York, ISBN: 10: 019282080X, pp: 400.

8. Indrajit Dube, 2007. Environmental JurisprudencePolluter's Liability. Lexis Nexis, ISBN: 9 78-818038-152-2, pp: 205-209.

9. Moltke, K.V., 1993. The last round: The general agreement on tariffs and trade in light of the earth summit. Environ. Law, 23: 519-520. http://www.encyclopedia.com/doc/1G113752522.html
10. Muschett, F.D. and C.L. Campbell, 1997. Principles of Sustainable Development. CRC Press, Florida, ISBN: 1574440799, pp: 176.

11. Esty, D., 1993. Beyond Rio: Trade and environment. Environ. Law, 23: 3-87. http://www.encyclopedia.com/doc/1G113752364.html

12. Goyal, A., 2006. The WTO and International Environmental Law: Towards Conciliation. 1st Edn., Oxford University Press, ISBN: 10: 0195677102, pp: 450.

13. Prasad, P.S., 2006. International Trade and Environment-Conflict and Compatability, 1st Edn., ICFAI University Press, ISBN: 8131413349.

14. UN., 2001. United Nations Environment Programme Report of the Governing Council. http://www.un.org/documents/ga/docs/56/a5625.pd $\mathrm{f}$

15. Nanda, V.P. and G. Pring, 2003. International Environmental Law and Policy for the 21st Century. Traditional Publisher, New York, ISBN: 1571051422, pp: 512.

16. Schoenbaum, T.J., 1992. Free International trade and protection of the environment: Irreconcilable conflict? Am. J. Int. Law, 86: 700-727. http://www.jstor.org/stable/2203788

17. Rao, P.K., 2002. International Environmental Law and Economics, Blackwell Publishers, ISBN: 0631218939, pp: 339.

18. Holtby, K.L., W.A. Kerr, J.E. Hobbs, 2007. International Environmental Liability and Barriers to Trade: Market Access and Biodiversity in the Biosafety Protocol. 1st Edn., Edward Elgar, ISBN: 9781847200976, pp: 166.

19. Werksman, J.D. and G.B. Woods, 1995. The EarthScan Reader in Sustainable Development, EarthScan Ltd., ISBN: 9781853832161, pp: 304.

20. Bodansky, D., J. Brunnee and E. Hey, 2007. The Oxford Handbook of International Environmental Law. 1st Edn., Oxford University Press, ISBN: 13: 9780199269709, pp: 1080.

21. WTO., 1996. Trade and environment. http://www.wto.org/english/tratop_e/envir_e/envir _e.htm

22. Cleveland, C.J. and I. Kubiszewski, 1992. Sustainable development and International environmental issues. Proceeding of the United Nations Conference on Environment and Development, June 3-4, Rio De Janerio, Brazil, http://www.eoearth.org/article/United_Nations_Co nference_on_Environment_and_Development_(U NCED),_Rio_de_Janeiro,_Brazil 
23. Hunter, D. and J. Salzam, 1998. International Environmental Law and Policy. West Publishing Company, ISBN: 10: 1566625890, pp: 1567.

24. Lester, S., B. Mercurio, A. Davies and K. Leither, 2008. World Trade Law-Text, Materials and Commentary. Hart Publishing, ISBN: 10: 1841136603, pp: 892.

25. Birnie, P., and A. Boyle, 2002. International Law and the Environment. 2nd Edn., Oxford University Press, ISBN: 10: 0198765533, pp: 832.

26. Shaw, S. and R. Schwartz, 2002. trade and environment in the WTO-state of play. World Trade, 36: 129.

27. Pratap, R., 2002. Trade and environment: Trends in international dispute settlement. Ind. J. Int. Law, 42: 451-488.

28. Rosser Jr. B., 2005. Institutional evolution and the environmental Kuznets curve. http://cob.jmu.edu/rosserjb/Inst.Ev.Kuznets.curve.d oc

29. Seymour J.R., 1982. A Predominantly Commercial Perspective in Environment and Trade-The Relation of International Trade and Environmental Policy. Rowman and Littlefield Pub inc., ISBN: 0865980322, pp: 220.
30. Krishna Iyer, J.V.R., 2004. Towards a Natural World-The Rights of Nature, Animals, Citizens and other Essays. Hope India, ISBN: 817871048X, pp: 721-725.

31. Bhatt, S. and. D. Nagchudhari, 1985. The Global Environment Movement-A New Hope for Mankind. Radiant Publishers, New Delhi, pp: 122.

32. Sears, P.B., 1965. The process of environmental change by man, in man's role in changing the face of Earth. http://www.historycooperative.org/cgibin/justtop.cgi?act=justtop\&url=http://www.history cooperative.org/journals/eh/10.3/rr_1.html 